\title{
Yoga Effects on Brain Health: A Systematic Review of the Current Literature
}

\author{
Neha P. Gothe ${ }^{\mathrm{a}, *}$, Imadh Khan ${ }^{\mathrm{a}}$, Jessica Hayes ${ }^{\mathrm{b}}$, Emily Erlenbach ${ }^{\mathrm{a}}$ and Jessica S. Damoiseaux ${ }^{\mathrm{b}}$ \\ ${ }^{a}$ Department of Kinesiology and Community Health, University of Illinois at Urbana Champaign \\ ${ }^{\mathrm{b}}$ Department of Psychology and Institute of Gerontology, Wayne State University
}

\begin{abstract}
Yoga is the most popular complementary health approach practiced by adults in the United States. It is an ancient mind and body practice with origins in Indian philosophy. Yoga combines physical postures, rhythmic breathing and meditative exercise to offer the practitioners a unique holistic mind-body experience. While the health benefits of physical exercise are well established, in recent years, the active attentional component of breathing and meditation practice has garnered interest among exercise neuroscientists. As the scientific evidence for the physical and mental health benefits of yoga continues to grow, this article aims to summarize the current knowledge of yoga practice and its documented positive effects for brain structure and function, as assessed with MRI, fMRI, and SPECT. We reviewed 11 studies examining the effects of yoga practice on the brain structures, function and cerebral blood flow. Collectively, the studies demonstrate a positive effect of yoga practice on the structure and/or function of the hippocampus, amygdala, prefrontal cortex, cingulate cortex and brain networks including the default mode network (DMN). The studies offer promising early evidence that behavioral interventions like yoga may hold promise to mitigate age-related and neurodegenerative declines as many of the regions identified are known to demonstrate significant age-related atrophy.
\end{abstract}

Keywords: Cognition, brain, yoga review

\section{INTRODUCTION}

The practice of yoga dates back over 2000 years to ancient India, with a focus on the unification of the mind, body, and spirit through the practice of physical movements, meditation and breathing exercises. Over the course of its lengthy existence, many different schools of yoga have emerged, each placing a different emphasis on the practice. However, despite their different philosophies and combinations of exercises, they all are integrated in the common theme of uniting the mind and body. Yoga's prominence in western civilization emerged in the late 20th century. Although a review of the PubMed search on yoga yields the earliest scientific studies dating to 1948,

\footnotetext{
*Correspondence to: Dr. Neha P. Gothe, Kinesiology and Community Health, University of Illinois at Urbana Champaign, Urbana, IL-61801. Tel.: +1 217300 6183; E-mail: npg@illinois. edu.
}

there has been an exponential increase in publications beginning in the 2000s (see Fig. 1). While its origins root from religious principles, modern day culture is primarily drawn to it for its relaxation benefits (meditation and breathing exercises) and stretching and strengthening movements (physical poses). According to the National Center for Complementary and Integrative Health (NCCIH), yoga is the most popular form of complementary therapy practiced by more than 13 million adults, with $58 \%$ of adults citing maintenance of health and well-being as their reason for practice [1]. One of the reasons for yoga's increase in popularity is its versatility, in that it can be taught at a range of different intensities. A systematic review by Larson-Meyer examined [2] the metabolic energy expenditure during Hatha yoga, the most widely practiced style of yoga in the United States. The review found that, while some specific yoga poses can be metabolically exerting (with energy expenditures $>3$ METS), most yoga practices 


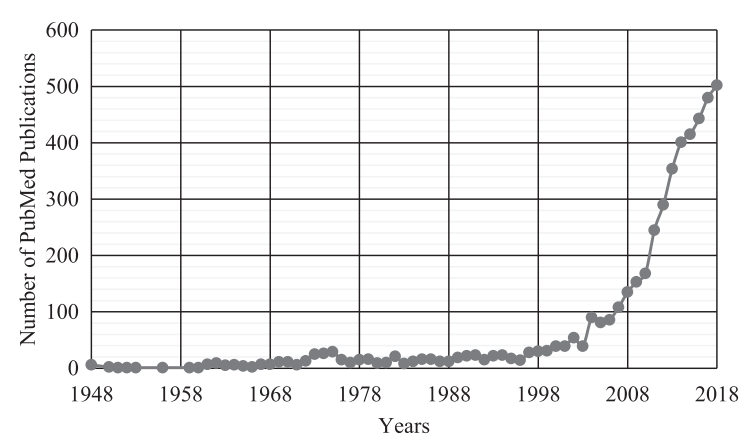

Fig. 1. Search results from PubMed featuring the term "yoga" in the title and/or abstract of publications over the years shows an exponential growth in yoga research beginning in the 2000 s.

fall under the American College of Sport Medicine's criteria of "light-intensity physical activity" (2-2.9 METS) [3]. Compared to traditional forms of aerobic and anaerobic exercise, the relatively low-impact, modifiable nature of yoga can offer a middle ground for individuals with movement limitations, clinical diagnoses, and is particularly suitable for aging populations. Yoga's focus on improving the self through both physical and mental practices incorporates more mindful elements absent in traditional forms of exercise.

Indeed, the practice of engaging the mind and body through meditation, breathing and physical poses has attracted significant attention from the medical community, and yoga has been frequently studied for its possible beneficial effects on physical and mental health outcomes. Systemic and meta-analytic reviews of randomized control trials have found positive associations between yoga practice and improvements in diabetes $[4,5]$, cardiovascular function [6], and musculoskeletal conditions [2,3]. There is also considerable evidence for the beneficial effects of yoga practice on mental health including anxiety [9], stress $[10,11]$ depression $[12,13]$ and overall mental health [14]. Typically, yoga has been studied as an adjunct therapy in these studies conducted with adults and older adults often with clinical diagnoses. For example, Lin and colleagues [15] conducted a meta-analysis assessing the effects of yoga on psychological health, quality of life, and physical health of patients with cancer. They concluded that the yoga groups showed significantly greater improvements in psychological health, as indicated by anxiety, depression, distress, and stress levels, when compared with the waitlist or supportive groups.

Yoga's acute and intervention effects on cognition are evident in a recent meta-analysis [16] which reported moderate effect sizes for attention, processing speed and executive function measures for studies conducted with adult populations. Yoga practice enables the practitioner to move in a controlled manner into modifiable physical postures concentrating initially on relaxing their body, breathing rhythmically, and developing awareness of the sensations in their body and thoughts in their mind. In addition to the physical benefits from sequentially completing the postures, the breathing (pranayama) and meditation exercises included in yoga are practiced to calm and focus the mind and develop greater self-awareness [17]. It is hypothesized that this combination of metacognitive thought and bodily proprioception during yoga practice could generalize to conventionally assessed cognitive functions including attention, memory, and higher-order executive functions. However, it is currently unknown if this relationship exists as a direct pathway, or if yoga indirectly influences cognitive functions through processes such as affective regulation. Negative affect including depression and stress are known to detrimentally impact both cognitive functioning [18] and brain structure [19] and systematic reviews discussed earlier have demonstrated the potential of yoga to improve anxiety, depression, stress and overall mental health.

Yoga has particularly gained traction as a research area of interest in its promising potential as a therapy to combat the alarming increase in age-related neurodegenerative diseases. Older adults are the fastest growing population in the US and around the world with over 2 billion people expected to be $\geq 60$ years of age by 2050 [20]. Age is the biggest risk factor for Alzheimer's disease, the most common cause of dementia in those aged 65 and older. In the absence of any effective treatments to cure the disease or manage its symptoms, researchers have explored the potential of modifying lifestyle behaviors such as nutrition and physical activity to drive beneficial plasticity of the aging brain and remediate age-related cognitive decline. Yoga may be an alternative form of physical activity which may help not only older adults achieve recommended levels of physical activity, but also for individuals who have disabilities or symptoms that prevent them from performing more vigorous forms of exercise.

The purpose of this review was to synthesize the current evidence for yoga's effect on brain structure and function among adults and identify the regions and neural networks impacted by its short-term or long-term practice. 


\section{METHODS}

\section{Literature search and study selection}

The aim of this review was to examine the role of 'holistic' yoga practice, i.e. studies that explored the role of yoga practice which included each of its three elements: yoga postures, yoga-based breathing exercise and yoga-based meditative exercises. We used the following databases to identify studies from inception to July 2019 that have examined effects of yoga on brain health: MEDLINE, PsychINFO, PubMed, Indian Council of Medical Research, and Cochrane. We used the following a priori search terms to identify all the relevant published articles: 'yoga', 'hatha yoga' and 'brain health', 'brain function', 'MRI', 'fMRI', 'brain volume' 'SPECT', 'PET'. Reference lists of relevant articles were also scanned to locate other published works.

Study inclusion criteria were peer reviewed and published cross-sectional, longitudinal or intervention studies examining the role of holistic yoga practice that included physical postures, breathing and meditation. Study outcomes needed to include brain health measures assessed using magnetic resonance imaging (MRI), including functional MRI (fMRI) or single photon emission computed tomography scan (SPECT) or position emission tomography (PET). Figure 2 presents the PRISMA flowchart that summarizes the study selection process. Studies examining the sole effects of meditation or mindfulness were excluded as they have been reviewed elsewhere $(21,22)$ and do not meet the holistic definition of yoga practice. After screening for inclusion criteria, 11 studies were included in this review. These studies were categorized based on the outcome variables measured, into two groups: "Effects of Yoga Practice on Brain Structure" that describes the structural characteristics of the brain associated with yoga practice, and "Effects of Yoga Practice on Brain Function" that describes investigations of regions showing differential activation or connectivity in the context of yoga practice.

\section{RESULTS}

\section{Study characteristics}

As seen in Table 1, this literature is very nascent, as evident from our literature search returning 11 relevant studies published between 2009 and 2019. Most of the studies $(n=6)$ were cross-sectional and there-

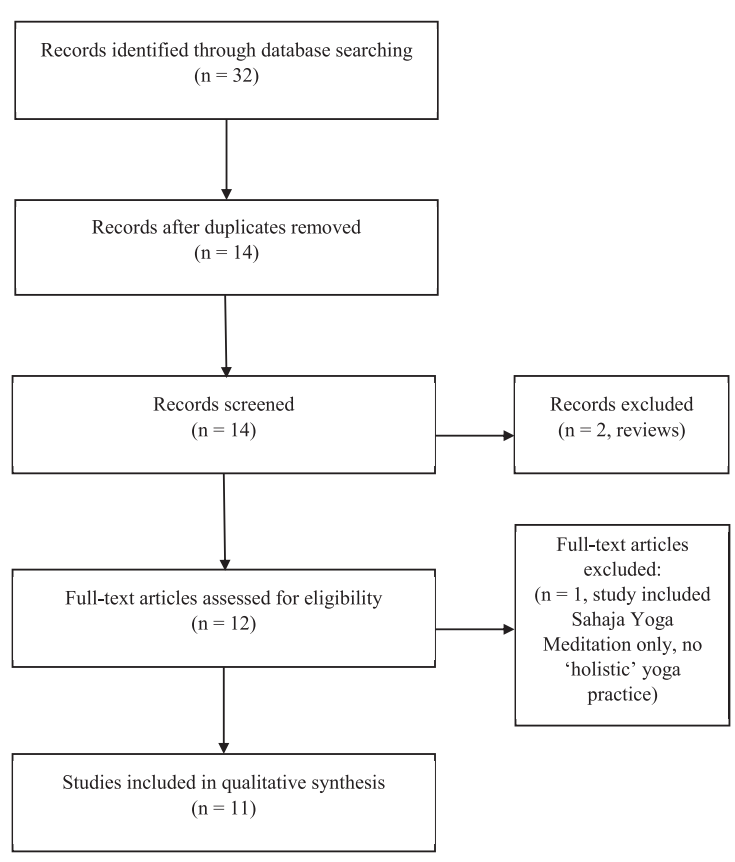

Fig. 2. Prisma flowchart.

fore exploratory in nature, whereas 5 intervention studies examined the yoga-brain outcome relationships over study durations ranging between 10 and 24 weeks. All studies have been conducted with adult populations, with 5 studies having a mean age greater than 65 years, suggesting older adult samples.

Various styles of yoga were reported across the studies, with a majority $(n=9)$ classified as Hatha yoga practice (a style that focuses on physical postures, breathing, and meditation). Other styles of yoga reported in the studies included Kundalini yoga with Kirtan Kriya $(n=2)$, which focuses more on mediation and the chanting of mantras, and Iyengar $(n=1)$ which is a type of Hatha yoga with a greater emphasis on anatomical detail and alignment. The 5 intervention studies ranged from 10 to 24 weeks and examined the brain health outcomes at baseline and end of the intervention. The frequency of yoga practice varied across the interventions ranging from once a week to biweekly to daily practice. Studies that compared brain health outcomes for yoga practitioners or experts with age- and or sex-matched controls typically included yoga practitioners with at least 3 or more years of regular (weekly or biweekly) yoga practice. None of these cross-sectional studies offered a standardized definition or specific criterion to define a yoga practitioner. Based on the studies included in this review, a yoga practitioner was defined as an indi- 
Table 1

Study characteristics of the 11 publications examining the role of yoga on brain structures and functioning

\begin{tabular}{|c|c|c|c|c|c|c|}
\hline $\begin{array}{l}\text { Study author } \\
\text { (Year) }\end{array}$ & $\begin{array}{l}\text { Sample size; } \\
\text { characteristics; } \\
\text { Mean Age; } \\
\text { Male:Female }\end{array}$ & Style of Yoga & Study design & $\begin{array}{l}\text { Categorization } \\
\text { of Yoga } \\
\text { Group/practitioner } \\
\text { and controls }\end{array}$ & $\begin{array}{l}\text { Imaging } \\
\text { methodology }\end{array}$ & Study findings \\
\hline Santaella (2019) & $\begin{array}{l}\mathrm{N}=40 ; \text { healthy } \\
\text { female older } \\
\text { adults }-20 \text { yoga } \\
\text { practitioners } \\
\text { and } 20 \text { controls; } \\
67.35 \text { years; } \\
0: 40\end{array}$ & Hatha & Cross-sectional & $\begin{array}{l}\text { 8+ years of at least } \\
\text { bi-weekly Hatha } \\
\text { yoga practice } \\
\text { vs. no yoga or } \\
\text { mindfulness } \\
\text { experience }\end{array}$ & $\begin{array}{l}\text { Resting-state } \\
\text { fMRI }\end{array}$ & $\begin{array}{l}\text { Greater resting-state } \\
\text { anteroposterior } \\
\text { functional } \\
\text { connectivity between } \\
\text { the medial prefrontal } \\
\text { cortex (MPFC) and } \\
\text { right angular gyrus } \\
\text { among yoga experts }\end{array}$ \\
\hline Garner (2019) & $\begin{array}{l}\mathrm{N}=102 ; \text { healthy } \\
\text { young adults- } \\
39 \text { randomized } \\
\text { to yoga, } 32 \text { to a } \\
\text { sport control } \\
\text { group, and } 31 \text { to } \\
\text { a passive control } \\
\text { group; } 22.8 \\
\text { years; } 16: 86\end{array}$ & Hatha & Intervention & $\begin{array}{l}\text { All yoga and sport } \\
\text { control } \\
\text { participants had } \\
\text { not practiced } \\
\text { yoga or similar } \\
\text { mind-body } \\
\text { exercises for at } \\
\text { least } 6 \text { months. }\end{array}$ & MRI & $\begin{array}{l}\text { Increase in right } \\
\text { hippocampal GM } \\
\text { density among yoga } \\
\text { group. }\end{array}$ \\
\hline Gothe (2018) & $\begin{array}{l}\mathrm{N}=26 ; \text { healthy } \\
\text { adults }-13 \text { yoga } \\
\text { experts and } 13 \\
\text { controls; } 35.75 \\
\text { years; } 2: 24\end{array}$ & Hatha & Cross-sectional & $\begin{array}{l}\text { 3+ years of } \\
\text { weekly yoga } \\
\text { experience vs. } \\
\text { no yoga or } \\
\text { mind-body } \\
\text { therapy } \\
\text { experience }\end{array}$ & $\begin{array}{l}\text { MRI+ } \\
\text { task-based } \\
\text { fMRI }\end{array}$ & $\begin{array}{l}\text { Larger GM volume in } \\
\text { the left hippocampus } \\
\text { among yoga experts } \\
\text { Lower dorsolateral } \\
\text { prefrontal cortex } \\
\text { (dlPFC) activity } \\
\text { during encoding } \\
\text { phase of working } \\
\text { memory task among } \\
\text { yoga experts }\end{array}$ \\
\hline Afonso (2017) & $\begin{array}{l}\mathrm{N}=42 ; \text { older } \\
\text { adults }-21 \\
\text { experts and } 21 \\
\text { controls; } 67.05 \\
\text { years; } 0: 21\end{array}$ & Hatha & Cross-sectional & $\begin{array}{c}\text { 8+ years of yoga } \\
\text { experience vs. } \\
\text { no yoga or } \\
\text { mindfulness } \\
\text { experience }\end{array}$ & MRI & $\begin{array}{l}\text { Greater cortical } \\
\text { thickness in left } \\
\text { prefrontal lobe } \\
\text { region, including } \\
\text { lateral middle frontal } \\
\text { gyrus, anterior and } \\
\text { dorsal superior frontal } \\
\text { gyrus among yoga } \\
\text { experts }\end{array}$ \\
\hline Yang (2016) & $\begin{array}{l}\mathrm{N}=25, \text { healthy } \\
\text { older adults } \\
\text { with } \mathrm{MCI}-14 \\
\text { randomized to } \\
\text { yogic } \\
\text { meditation and } \\
11 \text { to memory } \\
\text { enhancement } \\
\text { training; } 67.4 \\
\text { years; } 13: 12\end{array}$ & $\begin{array}{l}\text { Kirtan } \\
\text { Kriya+Kundalini } \\
\text { Yoga }\end{array}$ & Intervention & $\begin{array}{l}\text { 1-hour/week for } \\
12 \text { weeks + daily } \\
\text { homework }\end{array}$ & $\begin{array}{l}\mathrm{MRI}+{ }^{1} \mathrm{H}- \\
\mathrm{MRS}\end{array}$ & $\begin{array}{l}\text { Decrease in } \\
\text { choline-containing } \\
\text { compounds in } \\
\text { bilateral hippocampus } \\
\text { in the memory } \\
\text { enhancement training } \\
\text { group } \\
\text { Increased GM } \\
\text { volume in bilateral } \\
\text { hippocampal in the } \\
\text { memory enhancement } \\
\text { training group }\end{array}$ \\
\hline & & & & & & $\begin{array}{l}\text { No significant changes } \\
\text { in yoga group }\end{array}$ \\
\hline
\end{tabular}


Table 1

(Continued)

\begin{tabular}{|c|c|c|c|c|c|c|}
\hline $\begin{array}{l}\text { Study author } \\
\text { (Year) }\end{array}$ & $\begin{array}{l}\text { Sample size; } \\
\text { characteristics; } \\
\text { Mean Age; } \\
\text { Male:Female }\end{array}$ & Style of Yoga & Study design & $\begin{array}{l}\text { Categorization } \\
\text { of Yoga } \\
\text { Group/practitioner } \\
\text { and controls }\end{array}$ & $\begin{array}{l}\text { Imaging } \\
\text { methodology }\end{array}$ & Study findings \\
\hline Eyre (2016) & $\begin{array}{l}\mathrm{N}=25 \text {; healthy } \\
\text { older adults } \\
\text { with } \mathrm{MCI}-14 \\
\text { randomized to } \\
\text { yogic } \\
\text { meditation and } \\
11 \text { to memory } \\
\text { enhancement } \\
\text { training; } 67.4 \\
\text { years; } 13: 12\end{array}$ & $\begin{array}{l}\text { Kirtan } \\
\text { Kriya+Kundalini } \\
\text { Yoga }\end{array}$ & Intervention & $\begin{array}{l}\text { 1-hour/week for } \\
12 \text { weeks + daily } \\
\text { homework }\end{array}$ & $\begin{array}{l}\text { Resting-state } \\
\text { fMRI }\end{array}$ & $\begin{array}{l}\text { Improved verbal } \\
\text { memory } \\
\text { performance which } \\
\text { correlated with } \\
\text { changes in } \\
\text { functional } \\
\text { connectivity in the } \\
\text { DMN, significant } \\
\text { clusters included } \\
\text { the ACC, FMC, } \\
\text { PCC, MFG and } \\
\text { LOC among both } \\
\text { groups } \\
\text { Improved verbal } \\
\text { memory } \\
\text { performance } \\
\text { correlated with } \\
\text { increased } \\
\text { connectivity } \\
\text { between the default } \\
\text { mode network and } \\
\text { frontal medial } \\
\text { cortex, pregunal } \\
\text { anterior cingulate } \\
\text { cortex, right middle } \\
\text { frontal cortex, } \\
\text { posterior cingulate } \\
\text { cortex, and left } \\
\text { lateral occipital } \\
\text { cortex } \\
\text { Improved verbal } \\
\text { memory } \\
\text { performance } \\
\text { positively correlated } \\
\text { with increased } \\
\text { connectivity } \\
\text { between language } \\
\text { processing network } \\
\text { and left inferior } \\
\text { frontal gyrus } \\
\text { Improved visuospatial } \\
\text { memory } \\
\text { performance } \\
\text { correlated inversely } \\
\text { with connectivity } \\
\text { between superior } \\
\text { parietal network } \\
\text { and medial parietal } \\
\text { cortex }\end{array}$ \\
\hline
\end{tabular}


Table 1

(Continued)

\begin{tabular}{|c|c|c|c|c|c|c|}
\hline $\begin{array}{l}\text { Study author } \\
\text { (Year) }\end{array}$ & $\begin{array}{l}\text { Sample size; } \\
\text { characteristics; } \\
\text { Mean Age; } \\
\text { Male:Female }\end{array}$ & Style of Yoga & Study design & $\begin{array}{l}\text { Categorization } \\
\text { of Yoga } \\
\text { Group/practitioner } \\
\text { and controls }\end{array}$ & $\begin{array}{l}\text { Imaging } \\
\text { methodology }\end{array}$ & Study findings \\
\hline Villemure (2015) & $\begin{array}{l}\mathrm{N}=28 ; \text { healthy } \\
\text { adults }-14 \text { yoga } \\
\text { experts and } 14 \\
\text { controls; } 36.85 \\
\text { years; } 10: 18\end{array}$ & $\begin{array}{l}\text { All types (that } \\
\text { integrated } \\
\text { physical } \\
\text { postures, breath } \\
\text { control } \\
\text { exercises and } \\
\text { meditation.) }\end{array}$ & Cross-sectional & $\begin{array}{l}\text { No defined } \\
\text { criteria, } \\
\text { open-ended } \\
\text { questions to } \\
\text { determine yoga } \\
\text { expertise } \\
\text { resulting in } \\
\text { average yoga } \\
\text { experience } \\
\text { range of 6-16 } \\
\text { years }\end{array}$ & MRI & $\begin{array}{l}\text { No correlation } \\
\text { between age and } \\
\text { whole-brain total } \\
\text { GM volume among } \\
\text { yoga experts } \\
\text { (negative } \\
\text { correlation in } \\
\text { controls) } \\
\text { Positive correlation } \\
\text { between years of } \\
\text { yoga practice and } \\
\text { GM volume in left } \\
\text { mid-insula, left } \\
\text { frontal operculum, } \\
\text { left orbitofrontal } \\
\text { cortex and right } \\
\text { middle temporal } \\
\text { gyrus } \\
\text { Positive correlation } \\
\text { between weekly } \\
\text { hours of practice } \\
\text { and GM volume in } \\
\text { right primary } \\
\text { somatosensory } \\
\text { cortex and superior } \\
\text { parietal lobe, left } \\
\text { hippocampus, } \\
\text { midline } \\
\text { precuneus/posterior } \\
\text { cingulate cortices, } \\
\text { and right primary } \\
\text { visual cortex } \\
\text { Postures and } \\
\text { meditation } \\
\text { predicted } \\
\text { hippocampal, } \\
\text { precuneus/PCC and } \\
\text { somatosensory } \\
\text { cortex/superior } \\
\text { parietal lobule } \\
\text { volume } \\
\text { Meditation and } \\
\text { breathing predicted } \\
\text { primary visual } \\
\text { cortex, } \\
\text { precuneus/posterior } \\
\text { cingulate cortex } \\
\text { volume }\end{array}$ \\
\hline Hariprasad (2012) & $\begin{array}{l}\mathrm{N}=7 ; \text { healthy } \\
\text { older adults; age } \\
\text { range } 69-81 \\
\text { years; } 4: 3\end{array}$ & $\begin{array}{l}\text { Hatha - } \\
\text { Yogasanass, } \\
\text { pranayama, OM } \\
\text { chanting }\end{array}$ & Intervention & $\begin{array}{l}\text { 1-hour } 5 \text { days a } \\
\text { week for } 3 \\
\text { months }+3 \\
\text { months of home } \\
\text { practice }\end{array}$ & MRI & $\begin{array}{l}\text { Increased GM volume } \\
\text { in bilateral } \\
\text { hippocampus } \\
\text { (posterior region) } \\
\text { following yoga } \\
\text { intervention }\end{array}$ \\
\hline
\end{tabular}


Table 1

(Continued)

\begin{tabular}{|c|c|c|c|c|c|c|}
\hline $\begin{array}{l}\text { Study author } \\
\text { (Year) }\end{array}$ & $\begin{array}{l}\text { Sample size; } \\
\text { characteristics; } \\
\text { Mean Age; } \\
\text { Male:Female }\end{array}$ & Style of Yoga & Study design & $\begin{array}{l}\text { Categorization } \\
\text { of Yoga } \\
\text { Group/practitioner } \\
\text { and controls }\end{array}$ & $\begin{array}{l}\text { Imaging } \\
\text { methodology }\end{array}$ & Study findings \\
\hline Froeliger (2012b) & $\begin{array}{l}\mathrm{N}=14 ; \text { healthy } \\
\text { adults }-7 \text { yoga } \\
\text { experts and } 7 \\
\text { controls; } 35.95 \\
\text { years; } 2: 12\end{array}$ & Hatha & Cross-sectional & $\begin{array}{l}\text { 3+ years of yoga } \\
\text { experience with } \\
45+\text { min of } \\
\text { practice } 3-4 \\
\text { times per week } \\
\text { vs no yoga or } \\
\text { meditation } \\
\text { experience }\end{array}$ & MRI & $\begin{array}{l}\text { Greater GM volume } \\
\text { of frontal, limbic, } \\
\text { temporal, occipital, } \\
\text { and cerebellar } \\
\text { regions among yoga } \\
\text { experts } \\
\text { Fewer self-reported } \\
\text { cognitive failures } \\
\text { among yoga experts } \\
\text { Negative correlation } \\
\text { between cognitive } \\
\text { failures and GM } \\
\text { volume } \\
\text { Positive correlation } \\
\text { between years of } \\
\text { yoga experience } \\
\text { and GM volume }\end{array}$ \\
\hline Froeliger (2012a) & $\begin{array}{l}\mathrm{N}=14 ; \text { healthy } \\
\text { adults }-7 \text { yoga } \\
\text { experts and } 7 \\
\text { controls; } 35.95 \\
\text { years; } 2: 12\end{array}$ & Hatha & Cross-sectional & $\begin{array}{l}3+\text { years of yoga } \\
\text { experience with } \\
45+\text { min of } \\
\text { practice } 3-4 \\
\text { times per week } \\
\text { vs no yoga or } \\
\text { meditation } \\
\text { experience }\end{array}$ & $\begin{array}{l}\text { Task-based } \\
\text { fMRI }\end{array}$ & $\begin{array}{l}\text { Lower right dorsal } \\
\text { lateral prefrontal } \\
\text { cortex (i.e. MFG) } \\
\text { activity during } \\
\text { viewing of negative } \\
\text { and neutral } \\
\text { emotional images } \\
\text { among yoga experts } \\
\text { Greater left superior } \\
\text { frontal gyrus } \\
\text { activity during } \\
\text { Stroop task among } \\
\text { controls } \\
\text { Greater left } \\
\text { ventrolateral } \\
\text { prefrontal cortex } \\
\text { activity during } \\
\text { Stroop task with } \\
\text { presence of negative } \\
\text { emotional } \\
\text { distractors than } \\
\text { neutral emotional } \\
\text { distractors in yoga } \\
\text { experts (opposite } \\
\text { pattern for controls) } \\
\text { No correlation } \\
\text { between amygdala } \\
\text { activation to } \\
\text { viewing negative } \\
\text { emotional image } \\
\text { and task-related } \\
\text { changes in affect } \\
\text { among yoga experts } \\
\text { (decreases in } \\
\text { positive affect were } \\
\text { correlated with } \\
\text { increased amygdala } \\
\text { activation in } \\
\text { controls). }\end{array}$ \\
\hline
\end{tabular}


Table 1

(Continued)

\begin{tabular}{|c|c|c|c|c|c|c|}
\hline $\begin{array}{l}\text { Study author } \\
\text { (Year) }\end{array}$ & $\begin{array}{l}\text { Sample size; } \\
\text { characteristics; } \\
\text { Mean Age; } \\
\text { Male:Female }\end{array}$ & Style of Yoga & Study design & $\begin{array}{l}\text { Categorization } \\
\text { of Yoga } \\
\text { Group/practitioner } \\
\text { and controls }\end{array}$ & $\begin{array}{l}\text { Imaging } \\
\text { methodology }\end{array}$ & Study findings \\
\hline Cohen (2009) & $\begin{array}{l}\mathrm{N}=4 \text {; healthy } \\
\text { older adults } \\
\text { with } \\
\text { prehypertension } \\
\text { or stage } 1 \\
\text { hypertension; } \\
45 \text { years; } 2: 2\end{array}$ & Hatha - Iyengar & Intervention & $\begin{array}{l}\text { 1-hour bi-weekly } \\
\text { practice for } 6 \\
\text { weeks + 1-hour } \\
\text { weekly practice } \\
\text { and home DVD } \\
\text { (average } 20 \text { min } \\
\text { daily practice } \\
\text { reported) for } 6 \\
\text { weeks }\end{array}$ & $\begin{array}{l}\text { Injection of } \\
\text { Tc- } \\
\text { bicisate }+ \text { single } \\
\text { proton } \\
\text { emission } \\
\text { computed } \\
\text { tomography }\end{array}$ & $\begin{array}{l}\text { Decrease in average } \\
\text { cerebral blood flow } \\
\text { le ratio in right } \\
\text { amygdala, right } \\
\text { dorsal medial } \\
\text { cortex, and right } \\
\text { sensorimotor area } \\
\text { during baseline } \\
\text { scan following yoga } \\
\text { intervention } \\
\text { Increased activation in } \\
\text { right dorsal medial } \\
\text { frontal lobe, left } \\
\text { dorsal medial } \\
\text { frontal lobe, right } \\
\text { prefrontal cortex, } \\
\text { right sensorimotor } \\
\text { cortex, right inferior } \\
\text { frontal lobe, and } \\
\text { right superior } \\
\text { frontal lobe during } \\
\text { meditation } \\
\text { following yoga } \\
\text { intervention } \\
\text { Greater activity in the } \\
\text { left side of anterior } \\
\text { cingulate, } \\
\text { dorsomedial frontal } \\
\text { cortex, superior } \\
\text { temporal lobe } \\
\text { relative to the right } \\
\text { following yoga } \\
\text { intervention } \\
\text { Greater laterality } \\
\text { preference for the } \\
\text { left over the right } \\
\text { hemisphere during } \\
\text { meditation } \\
\text { compared to } \\
\text { baseline following } \\
\text { yoga intervention }\end{array}$ \\
\hline
\end{tabular}

vidual who had consistently practiced yoga for at least 3 years on a weekly basis.

\section{Effects of yoga practice on brain structure}

In order to identify the effects of yoga practice on brain structure, researchers have utilized MRI to investigate how the structure of the brain differs among those with experience practicing yoga (see Fig. 3).

\section{Cross-sectional studies examining group differences}

The majority of these studies have relied on comparing the brain structure of experienced yoga practitioners, with the brain structure of nonpractitioners, or yoga-naïve controls, to detect cross-sectional differences existing between the groups. Afonso et al. [23] found differences in cortical thickness among female adults over the age of 60 with 8 or more years of Hatha yoga experience compared to a non-practitioner control group. The 


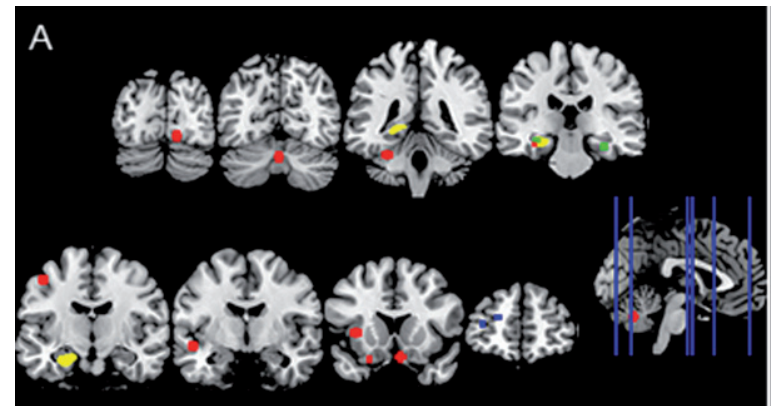

Red, Yellow, and Green: Gray matter volume (Froeliger et al., 2012b; Gothe et al., 2018; Hariprasad et al., 2013 respectively) Blue: Cortical thickness (Afonso et al., 2017) Pink: Gray matter density (Santaella et al., 2019)

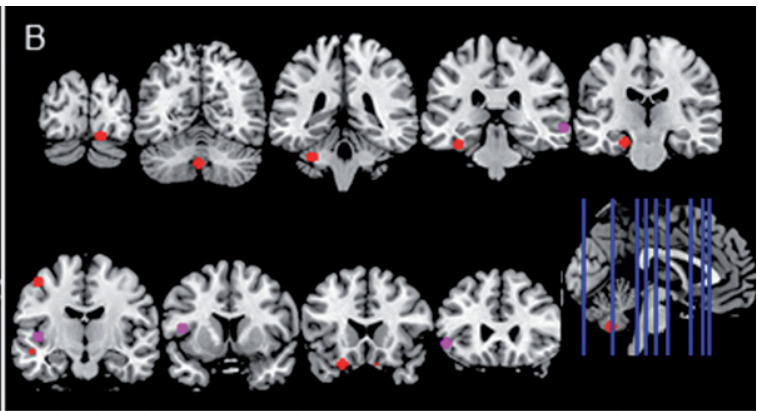

Red and Pink: Gray matter volume with years of yoga practice (Froeliger et al., 2012b; Villemure et al., 2015, respectively)

Fig. 3. Brain regions showing A) structural differences in yoga-practitioners compared to non-practitioners or B) a dose-dependent relationship between years of yoga practice and brain structure among practitioners. Yoga practitioners exhibited greater cortical thickness, gray matter (GM) volume, and GM density than non-practitioners in a variety of regions. Among yoga-practitioners, a positive relationship between the years of yoga practice and GM volume was also observed in a number of areas. All but one of the regions shown were created by making a $5 \mathrm{~mm}$ sphere around the coordinates provided in the studies reviewed. Since Gothe et al. (2018) did not investigate volume differences on a voxel-wise basis, a mask of the whole structure is shown.

yoga-practitioners exhibited greater cortical thickness in an area of the left prefrontal cortex that included part of the middle frontal and superior frontal gyri. Importantly, participants between groups were matched for the typical amount of non-yoga physical activity they engage in, suggesting that the differences in cortical thickness are not just due to a potentially greater levels of overall physical activity among yoga-practitioners.

Other studies that investigated cross-sectional differences in brain structure between yogapractitioners and non-practitioners primarily focused on detecting differences in gray matter (GM) volume rather than cortical thickness. Our own work [24] sought to determine whether the volume of the hippocampus, a subcortical structure that plays an important role in memory, differed between yogapractitioners with at least 3 years of experience compared to non-practitioners. We found the volume of the left hippocampus to be significantly greater among yoga-practitioners compared to age- and sexmatched controls with similar physical activity and fitness levels. We also tested differences between the thalamus and caudate nucleus, which are subcortical structures that served as control regions. No significant differences were found between the two groups, suggesting that yoga effects on the brain may be selective and similar to those observed in the aerobic exercise-cognition literature. Consistent with this result, another study [25] also identified volume differences in the left hippocampus and parahippocampal gyrus between healthy adults with and without yoga experience. A number of additional frontal (bilateral orbital frontal, right middle frontal, and left precentral gyri), temporal (left superior temporal gyrus), limbic (left parahippocampal gyrus, hippocampus, and insula), occipital (right lingual gyrus), and cerebellar regions were also larger among yoga-practitioners than non-practitioners. Given that this sample of yoga-practitioners reported fewer cognitive failures than their yoga-naïve counterparts, the researchers correlated the number of lapses in cognitive function that participants reported with the volume of regions where group differences were observed. A negative correlation was reported, such that higher numbers of cognitive failures were associated with smaller GM volumes in the frontal, limbic temporal, occipital, and cerebellar regions stated above.

Villemure and colleagues [26] investigated whether the correlation of age with total GM volume of the whole brain differed between a group of yogapractitioners and non-practitioners. While within the group of healthy adults without yoga experience, a negative correlation was observed between age and the total GM volume of the brain, no relationship was found between age and brain structure within the group of yoga-practitioners. However, the difference in slopes between the groups was not statistically significant. Non-practitioners did not exhibit larger 
or thicker brain structures compared to experienced yoga-practitioners in any of these studies.

\section{Intervention studies examining yoga training effects}

In comparison to the aforementioned crosssectional studies, studies employing yoga interventions have investigated how the structure of the brain changes as a result of relatively short-term yoga practice. Hariprasad and colleagues [27] measured changes in the GM volume of the bilateral hippocampus and the superior occipital gyrus, which served as a control region, following a 6-month yoga intervention. Participants consisted of healthy older adults who underwent an hour of formal training 5 days a week for 3 months and then completed the same daily regimen at home for an additional 3 months with regular booster training sessions. An increase in the volume of the bilateral hippocampus from preto post-intervention was observed; however, the sample of this study was quite small $(n=7)$ and did not compare these changes to changes in hippocampal volume of a control group. Another study [28] also evaluated changes in the GM volume of the bilateral hippocampus, as well as in the dorsal anterior cingulate cortex, but they did so in participants with mild cognitive impairment who completed a 12-week intervention consisting of weekly 1-hour sessions of either Kundalini yoga with Kirtan Kriya or memoryenhancement training. Both groups also completed 12 minutes of daily homework that was related to their intervention. Unlike previous studies, the results of a mixed effects model showed the volume change of the bilateral hippocampus did not differ between the two groups, but that the change in volume of the dorsal anterior cingulate cortex was different for the two intervention groups. Within the memory enhancement group, there was a trend toward increased volume of the dorsal anterior cingulate cortex following the intervention, a change that was not observed within the yoga group. It is possible that the shorter length of this intervention (12-weeks) in comparison to the 6-month intervention utilized by Hariprasad and colleagues [27] explains the differences in study results pertaining to hippocampal volume. However, since memory-enhancement training targets a single aspect of cognition and thus is likely to directly target areas involved in memory, it may not serve as an equal comparison group for yoga, whose effects are exerted in a more indirect fashion.
Garner and colleagues [29] investigated the impact of yoga training on GM density, which is related to a voxel's signal intensity and is reflective of the amount of gray matter within each voxel. They did this by comparing changes in GM density among healthy young adults after a 10-week intervention in which participants self-selected enrollment in a Hatha yoga, sport control, or passive control group. Although the yoga and sport control groups both underwent 10 hours of weekly practice which involved similar body movements, the meditation and breathing components of holistic yoga practice were not incorporated into the workouts performed by the sport control group. Unlike participants in these groups, who had not participated in their selected activities for at least 6 months prior to the intervention, participants in the passive control group did not alter any of their daily habits. No differences were observed between the yoga and passive control groups, but compared to the sport group, GM density of the yoga group was shown to increase in five regions and decrease in three regions following intervention. The only region to show an effect specific to the yoga intervention was the right hippocampus, which showed increased GM density over time within the yoga group and decreased GM density over time within the sport control group. Interestingly, this region showed significantly lower GM density at baseline for the yoga group compared to the two control groups. Neither gender or height differences were found to explain this, and no other sociodemographic characteristics were found to differ between the groups, but based on known links between the hippocampus, stress, and blood pressure, the authors suggest that individuals who are vulnerable to stress may have been driven to select yoga due to its known relaxation benefits.

\section{Dose-response relationships}

The second general strategy employed by researchers to investigate the effects of yoga practice on brain structure is to characterize the specific nature of the relationship between yoga practice and brain structure among experienced yoga practitioners. Such analyses primarily consist of examining the "dose-dependent" relationship between years of yoga practice and brain structure (see Fig. 3). However, evaluating how each of the different components of yoga practice (i.e. postures, breathing, meditation) is related to the structure of the brain is also of interest. Two of the cross-sectional studies already mentioned $(25,26)$ investigated relationships of this 
nature. After identifying regions of the brain in which yoga-practitioners exhibited greater GM volume than non-practitioners, Froeliger and colleagues (25) looked within these regions to identify areas where years of yoga practice was correlated with GM volume. They found that the extent of yoga experience within yoga-practitioners was positively related to volume of frontal, limbic, temporal, occipital, and cerebellar regions, while no regions showed a negative association between years of yoga practice and GM volume.

Villemure and colleagues [26] also sought to identify a dose-dependent relationship between GM volume, years of yoga practice and current weekly yoga practice as reported by the yoga-practitioners. Volumes of the left mid-insula, frontal operculum, orbital frontal cortex, and right middle temporal gyrus were positively correlated with years of yoga practice, while volumes of the left hippocampus, midline precuneus/posterior cingulate cortex, right primary visual cortex, and right primary somatosensory cortex/superior parietal lobe were positively related to the weekly number of hours spent practicing yoga. In addition to investigating this dose-dependent relationship between yoga practice and brain structure, the researchers conducted multiple regressions to evaluate how well each aspect of yoga practice predicted GM volume in the areas found to correlate with weekly yoga practice. Commonality analysis allowed them to divide the amount of variation in GM volume that was accounted for by all the predictors into the percentage of the effect unique to each predictor and common to each combination of 2 or more predictors. A combination of the posture and meditation components of yoga practice accounted for $42 \%$ of the explained variance in hippocampal GM, $41 \%$ in precuneus/posterior cingulate cortex GM, and $45 \%$ in primary visual cortex GM. Meanwhile, $44 \%$ of the explained variance in primary somatosensory cortex/superior parietal lobe GM volume was accounted for by the meditation and breathing components of yoga practice.

\section{Effects of yoga practice on brain function}

Although the majority of studies investigating yoga's relationship with the brain have focused on structural brain measures, a handful of studies $(n=5)$ have compared how brain functioning differs between those with and without yoga experience. Three of these studies were cross-sectional in nature, with two comparing task-related brain activation and the other comparing functional brain connectivity between experienced yoga-practitioners and nonpractitioners.

\section{Task-related fMRI findings}

Figure 3 represents the brain regions identified across the 3 studies based on the task-related fMRI findings. In addition to investigating differences in GM volume, our own work [24] evaluated how yogapractitioners and non-practitioners differed in brain function during subcomponents of a Sternberg working memory task. No differences between the groups were identified during the maintenance or retrieval portions of the task, but yoga-practitioners exhibited significantly less brain activation in the left dorsolateral prefrontal cortex (dlPFC) during encoding compared to yoga-naïve controls.

Froeliger and colleagues [30] used the same sample of yoga practitioners and non-practitioner controls who showed differences in GM volume [25] to investigate differences in task-related activation during an affective Stroop task. One focus of this fMRI study was to evaluate effects of yoga on emotional reactivity by considering the impact of group, the emotional valence of images viewed, and the interaction of group and valence on the BOLD response to viewing emotional images. A significant interaction was noted in the right dorsolateral prefrontal cortex (middle frontal gyrus), and further investigation demonstrated that the percent signal change in this region was greater when viewing neutral images compared to negative images among non-practitioners. Meanwhile, among yogapractitioners, the percent signal change in this region was lesser than that observed in non-practitioners regardless of whether the image had a negative or neutral emotional valence. Across all participants, the percent signal change in the dorsolateral prefrontal cortex was negatively correlated with the percent signal change in the amygdala when viewing negative images, but not when viewing neutral images. The second aim of the study was to identify how yoga experience alters the impact of emotional distraction on the Stroop-BOLD response. To investigate this, the main effects of group, the emotional valence of the distractor image, and the interaction between these on the BOLD response during the Stroop contrast (incongruent vs congruent number grids) were considered. The non-practitioners showed less activation in the left superior frontal gyrus compared 
to yoga-practitioners regardless of distractor image's emotional valence. Furthermore, the percent signal change of the left ventrolateral prefrontal cortex was greater among yoga-practitioners if a negative distractor was presented than if a neutral distractor was presented, while the opposite pattern was observed within the group of non-practitioners. Positive affect was shown to decrease significantly from baseline to the completion of the affective Stroop task among all participants and this change was positively correlated with the response to viewing negative images in the left amygdala. Furthermore, there was a significant interaction between this response and group, such that among non-practitioners a greater response to viewing negative emotional images was related to greater decreases in positive affect. Among yogapractitioners, however, this relationship between amygdala BOLD response to negative emotional images and change in affect was not present.

\section{Functional connectivity findings}

Unlike the previous two studies, which utilized fMRI to identify brain activation occurring during engagement in a cognitive task, a recent crosssectional study [31] utilized fMRI to identify whether yoga practice is related to functional brain connectivity. In response to interest surrounding yoga as a tool to combat aging, and the vulnerability of the default mode network (DMN) to typical and pathological aging processes, healthy older adults with at least 8 years of yoga experience were paired with age, education, and physical activity-matched yoganaive controls. Greater resting-state anteroposterior functional brain connectivity between the medial prefrontal cortex and right angular gyrus was observed among yoga practitioners compared to yoga-naïve controls. While a decrease in resting state functional connectivity is often associated with aging, this study suggests that yoga may reverse this age-related effect among older female subjects.

Other studies investigated longitudinal changes in the functional connectivity of the brain function following yoga intervention. One such study conducted by Eyre and colleagues [32] utilized fMRI to examine how the functional connectivity of the brain at rest changed following a 12-week intervention with either yoga or memory-enhancement training, as previously described in summarizing the results of Yang et al. [28]. Results showed that improvements in verbal memory recall were positively associated with changes in connectivity primarily within areas of the default mode network. Specifically, this effect was present in the pregenual anterior cingulate cortex, frontal medial cortex, posterior cingulate cortex, middle frontal gyrus, and lateral occipital cortex for both of the intervention groups. Similarly, changes in functional connectivity of the left inferior frontal gyrus, found in the language network, were also positively associated with changes in verbal memory recall for both groups. However, the relationship between changes in connectivity and memory was no longer significant in the posterior cingulate cortex or inferior frontal gyrus within the yoga intervention group after removal of an outlier. While an area within the superior parietal network near the precentral and postcentral gyri exhibited a negative relationship between changes in functional connectivity and changes in visuospatial memory, the authors interpreted this negative association to be reflective of enhanced efficiency following intervention. A 12week intervention was used in another study [33] to investigate whether changes in cerebral blood flow (CBF) measured with single-photon emission computed tomography were influenced by Iyengar yoga during baseline and meditation scans among four patients with mild hypertension. The right amygdala, dorsal medial cortex and sensorimotor areas showed decreases in baseline CBF following the intervention. Meanwhile, activation was greater during meditation in the right prefrontal cortex, sensorimotor cortex, inferior frontal lobe, superior frontal lobe and the right and left dorsal medial frontal lobes following yoga training. Furthermore, the greater activity of the left anterior cingulate, dorsomedial frontal cortex, and superior temporal lobe, relative to the right, was more prominent after the intervention. Following yoga training, laterality preference for the left over the right during meditation compared to baseline also became more pronounced.

\section{DISCUSSION}

Our review of the yoga-imaging literature suggests that behavioral mind-body interventions such as yoga practice can affect the anatomy of the brain. Yoga practice appears to be linked to anatomical changes in the frontal cortex, hippocampus, anterior cingulate cortex and insula. Throughout the studies reviewed, yoga practice showed a consistent positive relationship with measures of brain structure (i.e. GM volume, GM density, cortical thickness), such that regions showing an effect of yoga practice were greater in experts or had more gain 
following intervention. Differences in brain function between yoga-practitioners and non-practitioners have been observed in the dorsolateral prefrontal cortex, with yoga-practitioners showing less activation during both working memory and affective Stroop tasks. Additionally, yoga-practitioners differed from non-practitioners within the ventrolateral prefrontal cortex, superior frontal gyrus, and amygdala during other aspects of the affective Stroop task. Studies investigating changes in the functional connectivity of the brain following yoga practice have primarily identified increases in the default mode network, one of which found that those changes were related to memory performance.

Although the direction of differences in brain function between yoga-practitioners and nonpractitioners may be inconsistent, it is the interpretation of those differences and what they imply about the potential utility of yoga practice in maintaining brain health that are of ultimate interest. Given the complex nature of the brain, there is often more than one way something can exert an effect. This, in addition to the specific task being used, individual differences in the way participants strategize, and other differences in study design could account for differences in results across studies. While the nature of yoga's relationship with brain function seems less straightforward than it does with structure, the evidence still points toward yoga exerting a beneficial effect on brain function. Findings that link the pattern of brain functioning observed in yoga-practitioners to performance or health outcomes offer support for the beneficial influence of yoga on brain function.

Evidence suggests that global GM declines with age [34] while physical activity and cardiovascular fitness [35, 36] as well as mindfulness [21, 22] have shown to confer neuro-protective effects. The holistic practice of yoga combines physical activity in the form of postures with yoga-based meditative and breathing exercises. The findings from studies reviewed in this paper are therefore not surprising and suggest that yoga confers similar cortical neuroprotective effects. These findings could not only have a significant public health impact on cognitive aging but also call for exercise neuroscientists to design systematic trials to test the efficacy and effectiveness of yoga practice in comparison to other forms of physical activity and mindfulness practices.

A majority of the studies highlight changes in hippocampal volume following yoga practice. The hippocampus is known to be critically involved in learning and memory processes [37]. Yoga effects on the hippocampus are also aligned with findings from the aerobic exercise literature [38], as well as the mindfulness literature [39], suggesting that exercise alone and mindfulness alone, as well as a combination of the two in the form of yoga practice, have a positive effect on this critical brain structure implicated in age-related neurodegenerative diseases and chronic stress $[19,40]$. Other than the hippocampus, work of Froelinger and colleagues [25] suggests that yoga practitioners have higher GM volume in a number of regions including frontal (i.e., bilateral orbital frontal, right middle frontal, and left precentral gyri) (see Fig. 3), limbic (i.e., left parahippocampal gyrus, hippocampus, and insula), temporal (i.e., left superior temporal gyrus), occipital (i.e., right lingual gyrus) and cerebellar regions. Experimental and lesion studies indicate these brain structures are involved with tasks of cognitive control [41], inhibition of automatized or prepotent responses [42], the contextually appropriate selection and coordination of actions [43], and reward evaluation and decision making $[44,45]$. The cerebellum, a brain structure known for decades as integral to the precise coordination and timing of body movements [46], has more recently been acknowledged to be involved in cognition, specifically executive function [47, 48].

The studies reviewed also implicate the role of yoga in functioning of the dIPFC and the amygdala (see Fig. 4). Gothe et al. [24] found that yoga practitioners demonstrated decreased dIPFC activation

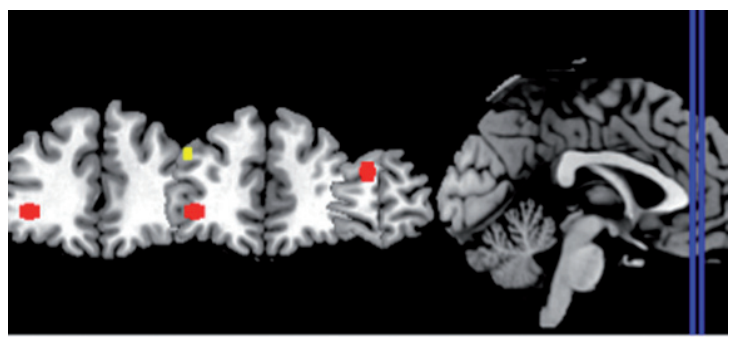

Red: Affective Stroop task (Froeliger et al., 2012a) Yellow: Encoding phase of Sternberg Working Memory task (Gothe et al., 2018)

Fig. 4. Brain regions showing differential task-related activation in yoga-practitioners. Yoga practitioners showed less activation than non-practitioners in the left dorsolateral prefrontal cortex during the encoding phase of a Sternberg Working Memory task (yellow). Yoga practitioners also showed less activation than nonpractitioners in the right dorsolateral prefrontal cortex and right superior frontal gyri, but more activation in the left ventrolateral prefrontal cortex during various aspects of an Affective Stroop task (red). All regions shown were created by making a $5 \mathrm{~mm}$ sphere around the coordinates provided in the studies reviewed. 
during the encoding phase of a working memory task in comparison to the controls. Froelinger et al. [30] also found yoga practitioners to be less reactive in the right dlPFC when viewing the negatively valanced images on the affective Stroop task. Task-relevant targets activate the dlPFC, whereas emotional distractors activate the amygdala [49]. Exerting cognitive control over emotional processes leads to increased activation in the dIPFC, with corresponding reciprocal deactivation in the amygdala $[50,51]$. The studies suggest that when emotional experience occurred within the context of a demanding task situation, yoga practitioners appeared to resolve emotional interference via recruitment of regions of the cortex that subserve cognitive control. Plausibly, these findings may indicate that yoga practitioners selectively recruit neurocognitive resources to disengage from negative emotional information processing and engage the cognitive demands presented by working memory and inhibitory control tasks demonstrating overall neurocognitive resource efficiency.

A network of neural structures including the frontal lobe, the anterior cingulate cortex, the inferotemporal lobe and the parietal cortex are known to be involved in cognitive operations including stimulus processing and memory updating $[52,53]$. Specifically, the anterior cingulate cortex is part of the brain's limbic system and has connections with multiple brain structures that process sensory, motor, emotional and cognitive information [54]. In our reviewed studies, Eyre et al. [32] found verbal memory performance to be correlated with increased connectivity between the pregenual anterior cingulate cortex, frontal medial cortex, posterior cingulate cortex, middle frontal gyrus, and lateral occipital cortex following a 12-week yoga intervention. Villemure et al. [26] also reported a positive correlation between the dose of weekly yoga practice and GM in the cingulate cortex. Collectively these results are promising and corroborate the aerobic exercise literature, as the anterior cingulate cortex is one of the brain structures that shows disproportional changes as a result of participation in moderate intensity physical activity [55]. Many of these regions are part of the default mode network, which is typically activated during rest and deactivated when an individual is engaged in an external task [56]. Following a yoga intervention, increases in connectivity of regions in the DMN were associated with improvements in verbal memory recall [32]. Given that functional connectivity of the DMN has been negatively associated with agerelated pathologies such as Alzheimer's disease [57], as well as in the context of typical aging [58], the increases in functional connectivity in regions of the DMN reported by Eyre et al. further indicate that yoga practice is a promising intervention for use among aging populations.

\section{Future directions}

Although yoga-cognition has emerged as a topical area in the field of exercise neuroscience, the studies are preliminary and lack the rigorous methodology that is applied in the exercise-cognition literature. Sample sizes for yoga studies have ranged from 4 to 102 participants and a majority of the work has been cross-sectional in nature. While the beauty of yoga lies in the diverse and modifiable combinations of postures, breathing and meditative exercises, this concurrently poses a challenge for scientists to compare findings across studies. Furthermore, there is no standardized definition for a yoga practitioner, nor a universal standard for certification. Of the yoga practitioners sampled in the reviewed studies, their experience ranged from regular practice 3-5 days a week for 3 to 16 years. This poses a challenge to compare research findings across studies.

Although cross-sectional studies limit us in our ability to draw casual conclusions, such a design can provide certain advantages over the use of interventional studies design in identifying the effects of yoga practice on the brain given that 9.3 years was the lowest average number of years of yoga practice reported by yoga-practitioners in these studies. Following yoga-practitioners for such an extended period in an intervention design would pose a variety of practical difficulties, and thus cross-sectional comparisons between yoga practitioners and yoga-naïve controls provide a unique opportunity to gain an idea of the maximal benefits that extensive yoga practice may lead to. Nonetheless, it is the promise of yoga as an intervention for individuals with various health issues that has sparked much of the growing interest in the effects of yoga practice on brain structure and function, since its established cognitive benefits and accessibility to people with a wide range of physical capabilities suggest it may be an effective intervention for typical and pathological cognitive decline among older adults. Yet for yoga interventions to have clinical utility in such circumstances, compliance to the intervention program is a necessity. None of the reviewed intervention studies provided information about participants' compliance and adherence to the yoga program. Future studies need to document 
and report attendance and adherence rates. The intervention studies also employed different frequencies, intensities and doses of yoga practice which resulted in heterogeneity across intervention designs as well.

While the reviewed studies examined the relationship between yoga and brain structure or function, only one [24] employed cognitive or behavioral assessments which correlate with the studied brain regions. Future studies should administer such assessments to establish if the neural changes produced by yoga practice are indeed manifested into improved cognitive performance and/or behavioral changes. Another limitation among the reviewed studies is lack of reported data on the lifestyle characteristics of yoga practitioners. A national survey [59] found that, compared to the US average, yoga practitioners are more likely to be highly physically active, nonobese, and well-educated - each of which [60-62] are known to individually contribute to positive changes in brain structure and function. The same survey also found that yoga practitioners are almost four times more likely to follow vegetarian or plant-based diets compared to the US population which could also contribute to brain health [63]. Future research should examine how the lifestyle characteristics of yoga practitioners may interact with the physical practice of yoga and contribute towards brain function and structure.

Unlike intervention studies and randomized trials, the design of cross-sectional studies limits the control researchers can exert on possible confounding or mediating variables. Most of the cross-sectional studies compare the brains of yoga practitioners with several years of experience to age- and sexmatched yoga-naive controls. However, only three of these studies matched the groups on the levels of physical activity between the groups or their cardiovascular fitness levels. Moving forward, researchers should conduct well-powered yoga interventions with appropriate controls to examine the neuroimaging outcomes. A variety of cognitive measures and neuroimaging analysis techniques have been used in the literature. Perhaps a foundation would be to test yoga interventions against the established evidence for aerobic exercise and mindfulness practices. Designing randomized controlled trials with exercise and mindfulness comparison groups will allow us to further the literature with the goal of identifying the unique and holistic effects of exercise vs. mindfulness vs. yoga practice.

The literature is too nascent, and it would be premature to dive into comparisons between different styles of yoga practice. This is evident from the studies reviewed as none of them compared the effectiveness of one style of yoga versus another. This question is intertwined with the 'holistic' definition of yoga practice as different styles of yoga place greater or lesser emphasis on one or more elements of physical postures, breathing, and meditation. Wellpowered randomized control trials are needed not only to identify the 'active ingredient' that is driving the yoga effects on brain health, but also examine the synergistic neuro-protective effects of these elements. Lastly, it remains to be determined whether web-based yoga interventions will be as effective as in-person yoga interventions which were primarily utilized in the reviewed papers. There has been an exponential growth in the development of mobile health apps [64] and it remains to be determined whether web-delivered yoga interventions will be as effective as in-person often group based interventions.

\section{CONCLUSION}

This review of literature reveals promising early evidence that yoga practice can positively impact brain health. Studies suggest that yoga practice may have an effect on the functional connectivity of the DMN, the activity of the dorsolateral prefrontal cortex while engaged in cognitive tasks, and the structure of the hippocampus and prefrontal cortexall regions known to show significant age-related changes $[65,66]$. Therefore, behavioral interventions like yoga may hold promise to mitigate age-related and neurodegenerative declines. Systematic randomized trials of yoga and its comparison to other exercise-based interventions, as well as long term longitudinal studies on yoga practitioners are needed to identify the extent and scope of neurobiological changes. We hope this review can offer the preliminary groundwork for researchers to identify key brain networks and regions of interest as we move toward advancing the neuroscience of yoga.

\section{Author contributions}

NG, JD - conceptualization, analyses and writing. $\mathrm{JH}-$ structuring and writing results, figures and tables. IK - review of studies, extraction of data and preparation of Table 1. EE - revision and writing of the manuscript. 


\section{CONFLICT OF INTEREST}

The authors have no conflict of interest to report.

\section{REFERENCES}

[1] Clarke TC, Black LI, Stussman BJ, Barnes PM, Nahin RL. Trends in the use of complementary health approaches among adults: United States, 2002-2012. Natl Health Stat Report. 2015;(79): 1.

[2] Larson-Meyer DE. A Systematic Review of the Energy Cost and Metabolic Intensity of Yoga. Med Sci Sports Exerc. 2016 Aug;48(8):1558-69.

[3] Swain DP, Brawner CA, Medicine AC of S. ACSM's resource manual for guidelines for exercise testing and prescription. Wolters Kluwer Health/Lippincott Williams \& Wilkins; 2014.

[4] Aljasir B, Bryson M, Al-Shehri B. Yoga Practice for the Management of Type II Diabetes Mellitus in Adults: A systematic review. Evid Based Complement Alternat Med [Internet]. 2010 Dec [cited 2011 Aug 20];7(4):399-408. Available from: http://www. pubmedcentral.nih.gov/articlerender.fcgi? $\operatorname{artid}=2892348 \&$ tool $=$ pmcentrez\&rendertype $=$ abstract

[5] Innes KE, Vincent HK. The influence of yoga-based programs on risk profiles in adults with type 2 diabetes mellitus: a systematic review. Evid Based Complement Alternat Med [Internet]. 2007 Dec [cited 2011 Aug 11];4(4):469-86. Available from: http://www. pubmedcentral.nih.gov/articlerender.fcgi?artid $=2176136 \&$ tool $=$ pmcentrez\&rendertype $=$ abstract

[6] Chu P, Gotink RA, Yeh GY, Goldie SJ, Hunink MGM. The effectiveness of yoga in modifying risk factors for cardiovascular disease and metabolic syndrome: A systematic review and meta-analysis of randomized controlled trials. Eur $\mathbf{J}$ Prev Cardiol. 2016;23(3):291-307.

[7] Raub J a. Psychophysiologic effects of Hatha Yoga on musculoskeletal and cardiopulmonary function: a literature review. J Altern Complement Med [Internet]. 2002 Dec;8(6):797-812. Available from: http://www.ncbi. nlm.nih.gov/pubmed/12614533

[8] Ward L, Stebbings S, Cherkin D, Baxter GD. Yoga for functional ability, pain and psychosocial outcomes in musculoskeletal conditions: a systematic review and meta-analysis. Musculoskeletal Care. 2013 Dec;11(4):203-17.

[9] Kirkwood G, Rampes H, Tuffrey V, Richardson J, Pilkington K. Yoga for anxiety: a systematic review of the research evidence. Br J Sports Med [Internet]. 2005 Dec [cited 2011 Jul 1];39(12):884-91; discussion 891. Available from: http://www.pubmedcentral.nih.gov/articlerender.fcgi?artid $=1725091 \&$ tool $=$ pmcentrez $\&$ rendertype $=$ abstract

[10] Chong C, Tsunaka M, Tsang H, Chan E, Cheung W. Effects of Yoga on Stress Managmenet in Healthy Adults: A Systematic Review. Altern Ther. 2011;17(1):32-8.

[11] Pascoe MC, Bauer IE. A systematic review of randomised control trials on the effects of yoga on stress measures and mood. J Psychiatr Res. 2015;68:270-82.

[12] Pilkington K, Kirkwood G, Rampes H, Richardson J. Yoga for depression: the research evidence. J Affect Disord [Internet]. 2005 Dec [cited 2011 Jul 9];89(1-3):13-24. Available from: http://www.ncbi.nlm.nih.gov/pubmed/16185770
[13] Cramer H, Lauche R, Langhorst J, Dobos G. Yoga for depression: a systematic review and meta-analysis. Depress Anxiety. 2013 Nov;30(11):1068-83.

[14] Bussing A, Michalsen A, Khalsa SBS, Telles S, Sherman KJ. Effects of yoga on mental and physical health: a short summary of reviews. Evid Based Complement Alternat Med. 2012;2012:165410.

[15] Lin K-Y, Hu Y-T, Chang K-J, Lin H-F, Tsauo J-Y. Effects of yoga on psychological health, quality of life, and physical health of patients with cancer: a meta-analysis. Evid Based Complement Alternat Med [Internet]. 2011 Jan [cited 2011 Jul 27];2011:659876. Available from: http://www.pubmedcentral.nih.gov/articlerender.fcgi?artid $=3062158 \&$ tool $=$ pmcentrez\&rendertype $=$ abstract

[16] Gothe NP, McAuley E. Yoga and Cognition: A MetaAnalysis of Chronic and Acute Effects. Psychosom Med. 2015;77(7)

[17] Morone NE, Greco CM. Mind-body interventions for chronic pain in older adults: a structured review. Pain Med [Internet]. 2007 [cited 2011 Oct 23];8(4):359-75. Available from: http://www.ncbi.nlm.nih.gov/pubmed/17610459

[18] Chepenik LG, Cornew LA, Farah MJ. The influence of sad mood on cognition. Emotion. 2007;7(4):802.

[19] Woon FL, Sood S, Hedges DW. Hippocampal volume deficits associated with exposure to psychological trauma and posttraumatic stress disorder in adults: a metaanalysis. Prog Neuro-Psychopharmacology Biol Psychiatry. 2010;34(7):1181-8.

[20] United Nations. Department of International Economic and Social Affairs. Population Division. World Population Ageing 2013. 2013; Available from: https://www.un.org/en/ development/desa/population/publications/pdf/ageing/Wor ldPopulationAgeing2013.pdf

[21] Chiesa A, Calati R, Serretti A. Does mindfulness training improve cognitive abilities? A systematic review of neuropsychological findings. Clin Psychol Rev [Internet]. 2011 Apr [cited 2011 Jul 29];31(3):449-64. Available from: http://www.ncbi.nlm.nih.gov/pubmed/21183265

[22] Canter PH, Ernst E. The cumulative effects of Transcendental Meditation on cognitive function-a systematic review of randomised controlled trials. Wien Klin Wochenschr. 2003 Nov;115(21-22):758-66.

[23] Afonso RF, Balardin JB, Lazar S, Sato JR, Igarashi N, Santaella DF, et al. Greater cortical thickness in elderly female yoga practitioners-a cross-sectional study. Front Aging Neurosci. 2017;9:201.

[24] Gothe NP, Hayes JM, Temali C, Damoiseaux JS Differences in Brain Structure and Function Among Yoga Practitioners and Controls. Front Integr Neurosci. 2018;12:26.

[25] Froeliger B, Garland EL, McClernon FJ. Yoga meditation practitioners exhibit greater gray matter volume and fewer reported cognitive failures: results of a preliminary voxel-based morphometric analysis. Evid Based Complement Alternat Med. 2012;2012:821307.

[26] Villemure C, Čeko M, Cotton VA, Bushnell MC. Neuroprotective effects of yoga practice: age-, experience-, and frequency-dependent plasticity. Front Hum Neurosci. 2015 May;9:281.

[27] Hariprasad VR, Varambally S, Shivakumar V, Kalmady SV, Venkatasubramanian G, Gangadhar $\mathrm{BN}$. Yoga increases the volume of the hippocampus in elderly subjects. Indian J Psychiatry [Internet]. 2013 Jul;55(Suppl 3):S394-6. Available from: http://www.ncbi. nlm.nih.gov/pmc/articles/PMC3768219/ 
[28] Yang H, Leaver AM, Siddarth P, Paholpak P, Ercoli L, St Cyr NM, et al. Neurochemical and neuroanatomical plasticity following memory training and yoga interventions in older adults with mild cognitive impairment. Front Aging Neurosci. 2016;8:277.

[29] Garner M, Reith W, Krick C, Garner M. 10-Week Hatha Yoga Increases Right Hippocampal Density Compared to Active and Passive Control Groups: A Controlled Structural cMRI Study. 2019;1-11.

[30] Froeliger BE, Garland EL, Modlin LA, McClernon J. Neurocognitive correlates of the effects of yoga meditation practice on emotion and cognition: a pilot study. Front Integr Neurosci [Internet]. 2012;6(March 2016):48. Available from: http://journal.frontiersin.org/ article/10.3389/fnint.2012.00048/abstract

[31] Santaella DF, Balardin JB, Afonso RF, Giorjiani GM, Sato JR, Lacerda SS, et al. Greater Anteroposterior Default Mode Network Functional Connectivity in Long-Term Elderly Yoga Practitioners. 2019;11(July):1-7.

[32] Eyre HA, Acevedo B, Yang H, Siddarth P, Van Dyk K, Ercoli $\mathrm{L}$, et al. Changes in Neural Connectivity and Memory Following a Yoga Intervention for Older Adults: A Pilot Study. J Alzheimers Dis. 2016;52(2):673-84.

[33] Cohen DL, Wintering N, Tolles V, Townsend RR, Farrar JT, Galantino M Lou, et al. Cerebral blood flow effects of yoga training: preliminary evaluation of 4 cases. J Altern Complement Med [Internet]. 2009 Jan [cited 2011 Oct 28];15(1):9-14. Available from: http://www.pubmedcentral.nih.gov/articlerender.fcgi?artid $=3155099 \&$ tool $=$ pmcentrez\&rendertype $=$ abstract

[34] Walhovd KB, Westlye LT, Amlien I, Espeseth T, Reinvang I, Raz N, et al. Consistent neuroanatomical age-related volume differences across multiple samples. Neurobiol Aging. 2011;32(5):916-32.

[35] Colcombe SJ, Kramer AF, Erickson KI, Scalf P, McAuley E, Cohen NJ, et al. Cardiovascular fitness, cortical plasticity, and aging. Proc Natl Acad Sci U S A. 2004;101(9): 3316-21.

[36] McAuley E, Kramer AF, Colcombe SJ. Cardiovascular fitness and neurocognitive function in older Adults: a brief review. Brain Behav Immun [Internet]. 2004 May [cited 2011 Sep 9];18(3):214-20. Available from: http://linkinghub.elsevier.com/retrieve/pii/S088915910300 2216

[37] Squire LR. Memory and the hippocampus: a synthesis from findings with rats, monkeys, and humans. Psychol Rev. 1992;99(2):195.

[38] Erickson KI, Voss MW, Prakash RS, Basak C, Szabo A, Chaddock L, et al. Exercise training increases size of hippocampus and improves memory. Proc Natl Acad Sci. 2011;108(7):3017-22.

[39] Hölzel BK, Carmody J, Vangel M, Congleton C, Yerramsetti SM, Gard T, et al. Mindfulness practice leads to increases in regional brain gray matter density. Psychiatry Res Neuroimaging. 2011;191(1):36-43.

[40] Joels M. Functional actions of corticosteroids in the hippocampus. Eur J Pharmacol. 2008 Apr;583(2-3):312-21.

[41] Talati A, Hirsch J. Functional specialization within the medial frontal gyrus for perceptual go/no-go decisions based on "what,"“when," and "where" related information: an fMRI study. J Cogn Neurosci. 2005;17(7):981-93.

[42] Aron AR, Fletcher PC, Bullmore ET, Sahakian BJ, Robbins TW. Stop-signal inhibition disrupted by damage to right inferior frontal gyrus in humans. Nat Neurosci. 2003;6(2):115.
[43] Rushworth MFS, Walton ME, Kennerley SW, Bannerman DM. Action sets and decisions in the medial frontal cortex. Trends Cogn Sci. 2004;8(9):410-7.

[44] Kringelbach ML, Rolls ET. The functional neuroanatomy of the human orbitofrontal cortex: evidence from neuroimaging and neuropsychology. Prog Neurobiol. 2004;72(5):341-72.

[45] Damasio AR. The somatic marker hypothesis and the possible functions of the prefrontal cortex. Philos Trans R Soc London Ser B Biol Sci. 1996;351(1346):1413-20.

[46] Llinás R, Welsh JP. On the cerebellum and motor learning. Curr Opin Neurobiol. 1993;3(6):958-65.

[47] Sokolov AA, Miall RC, Ivry RB. The cerebellum: adaptive prediction for movement and cognition. Trends Cogn Sci. 2017;21(5):313-32.

[48] Koziol LF, Budding DE, Chidekel D. From movement to thought: executive function, embodied cognition, and the cerebellum. The Cerebellum. 2012;11(2):505-25.

[49] Yamasaki H, LaBar KS, McCarthy G. Dissociable prefrontal brain systems for attention and emotion. Proc Natl Acad Sci U S A. 2002 Aug;99(17):11447-51.

[50] Ochsner KN, Bunge SA, Gross JJ, Gabrieli JDE. Rethinking feelings: an FMRI study of the cognitive regulation of emotion. J Cogn Neurosci. 2002 Nov;14(8):1215-29.

[51] Ochsner KN, Gross JJ. Cognitive Emotion Regulation: Insights from Social Cognitive and Affective Neuroscience. Curr Dir Psychol Sci. 2008 Apr;17(2):153-8.

[52] Carter CS, Botvinick MM, Cohen JD. The contribution of the anterior cingulate cortex to executive processes in cognition. Rev Neurosci. 1999;10(1):49-58.

[53] Culham JC, Kanwisher NG. Neuroimaging of cognitive functions in human parietal cortex. Curr Opin Neurobiol. 2001;11(2):157-63.

[54] Bush, Luu, Posner. Cognitive and emotional influences in anterior cingulate cortex. Trends Cogn Sci. 2000 Jun;4(6):215-22.

[55] Hillman CH, Erickson KI, Kramer AF. Be smart, exercise your heart: exercise effects on brain and cognition. Nat Rev Neurosci. 2008 Jan;9(1):58-65.

[56] Buckner RL, Andrews-Hanna JR, Schacter DL. The brain's default network. Ann N Y Acad Sci. 2008;1124(1):1-38.

[57] Andrews-Hanna JR, Snyder AZ, Vincent JL, Lustig C, Head $\mathrm{D}$, Raichle ME, et al. Disruption of large-scale brain systems in advanced aging. Neuron. 2007;56(5):924-35.

[58] Damoiseaux JS, Beckmann CF, Arigita EJS, Barkhof F, Scheltens P, Stam CJ, et al. Reduced resting-state brain activity in the "default network" in normal aging. Cereb cortex. 2008;18(8):1856-64.

[59] Ross A, Friedmann E, Bevans M, Thomas S. National survey of yoga practitioners: Mental and physical health benefits. Complement Ther Med [Internet]. 2013 Aug 1 [cited 2019 Aug 13];21(4):313-23. Available from: https://www.sciencedirect.com/science/article/pii/S096522 9913000630

[60] Kramer AF, Erickson KI, Colcombe SJ. Exercise, cognition, and the aging brain. J Appl Physiol [Internet]. 2006 Oct [cited 2011 Jul 20];101(4):1237-42. Available from: http://www.ncbi.nlm.nih.gov/pubmed/16778001

[61] Dye L, Boyle NB, Champ C, Lawton C. The relationship between obesity and cognitive health and decline. Proc Nutr Soc. 2017;76(4):443-54.

[62] Albert MS, Jones K, Savage CR, Berkman L, Seeman T, Blazer D, et al. Predictors of cognitive change in older persons: MacArthur studies of successful aging. Psychol Aging. 1995;10(4):578. 
[63] van Praag H. Exercise and the brain: something to chew on. Trends Neurosci. 2009;32(5):283-90.

[64] Vital WC. UN Foundation-Vodafone Foundation Partnership. 2009. mHealth for Development: The Opportunity of Mobile Technology for Healthcare in the Developing World.
[65] Grady C. The cognitive neuroscience of ageing. Nat Rev Neurosci. 2012;13(7):491-505.

[66] Toga AW. Brain mapping: An encyclopedic reference. Academic Press; 2015. 